\title{
Photochemical activation of MH3-B1/rGel: a HER2-targeted treatment approach for ovarian cancer
}

\author{
Bente Bull-Hansen ${ }^{1}$, Maria B. Berstad ${ }^{1}$, Kristian Berg$^{1}$, Yu Cao ${ }^{2,5}$, Ellen Skarpen ${ }^{3}$, \\ Ane Sofie Fremstedal ${ }^{1}$, Michael G. Rosenblum ${ }^{2}$, Qian Peng ${ }^{4}$ and Anette Weyergang ${ }^{1}$ \\ ${ }^{1}$ Department of Radiation Biology, Institute for Cancer Research, Norwegian Radium Hospital, Oslo University Hospital, Oslo, \\ Norway \\ ${ }^{2}$ Immunopharmacology and Targeted Therapy Laboratory, Department of Experimental Therapeutics, M.D. Anderson Cancer \\ Center, Houston, TX, USA \\ ${ }^{3}$ Department of Biochemistry, Institute for Cancer Research, Norwegian Radium Hospital, Oslo University Hospital, Olso, \\ Norway \\ ${ }^{4}$ Department of Pathology, Norwegian Radium Hospital, Oslo University Hospital, Oslo, Norway \\ ${ }^{5}$ Current address: The Scripps Research Institute, Department of Chemistry, La Jolla, CA, USA \\ Correspondence to: Anette Weyergang, email: anette.weyergang@rr-research.no
}

Keywords: ovarian cancer, HER2/neu/ErbB2, immunotoxin, photochemical internalization, photodynamic

Received: October 13,2014 Accepted: March 11, $2015 \quad$ Published: April 14, 2015

This is an open-access article distributed under the terms of the Creative Commons Attribution License, which permits unrestricted use, distribution, and reproduction in any medium, provided the original author and source are credited.

\section{ABSTRACT}

HER2-targeted therapy has been shown to have limited efficacy in ovarian cancer despite frequent overexpression of this receptor. Photochemical internalization (PCI) is a modality for cytosolic drug delivery, currently undergoing clinical evaluation. In the present project we studied the application of PCI in combination with the HER2targeted recombinant fusion toxin, MH3-B1/rGel, for the treatment of ovarian cancer. The SKOV-3 cell line, resistant to trastuzumab- and MH3-B1/rGel- monotherapy, was shown to respond strongly to PCI of MH3-B1/rGel to a similar extent as observed for the treatment-sensitive SK-BR-3 breast cancer cells. Extensive hydrolytic degradation of $\mathrm{MH3}-\mathrm{B1} / \mathrm{rGel}$ in acidic endocytic vesicles was indicated as the mechanism of MH3-B1/rGel resistance in SKOV-3 cells. This was shown by the positive Pearson's correlation coefficient between Alexa488-labeled MH3-B1/rGel and Lysotracker in SKOV-3 cells in contrast to the negative Pearson's correlation coefficient in SKBR-3 cells. The application of PCI to induce the release of MH3-B1/rGel was also demonstrated to be effective on SKOV-3 xenografts. Application of PCI with MH3-B1/ rGel was further found highly effective in the HER2 expressing HOC-7 and NuTu-19 ovarian cancer cell lines. The presented results warrant future development of PCI in combination with MH3-B1/rGel as a novel therapeutic approach in preclinical models of ovarian cancer.

\section{INTRODUCTION}

Ovarian cancer is the most lethal of gynecologic cancers. It is often diagnosed at a late stage and the sensitivity to available anticancer therapeutics is highly limited. New treatment approaches are therefore warranted for the management of this disease. HER2 overexpression is most commonly associated with breast cancer where HER2 overexpression is found in 20-30 \% of the cases [1]. Several HER2-targeted therapeutics have been approved for clinical use in the treatment of breast cancer. However, despite the success of HER2-targeted drugs in treating breast cancer, de novo as well as acquired resistance are major limitations in clinical practice [2], leaving patients with very limited treatment options. In case of ovarian cancer with known HER2 expression, several HER2targeted drugs have been evaluated in clinical trials [3, $4,5]$. However, no HER2-targeted drug has so far been approved for clinical use, despite HER2 overexpression being reported in up to $35 \%$ of all ovarian cancers [6, 7]. New HER2-targeted modalities with increased toxicity and less potential for development of resistance should therefore be an interesting approach for future treatment of ovarian cancer. 
Increased toxicity of HER2-targeted drugs may be achieved through the utilization of single-chain HER2 antibody-based immunotoxins. Such constructs have been proven highly HER2 specific in vitro and induce considerable tumor growth delay in several animal models $[8,9,10,11]$. The toxin component in such drugs acts by inhibition of protein synthesis and provides increased cytotoxic potential compared to clinically available HER2-targeted monoclonal antibodies (mAbs) and tyrosine kinase inhibitors (TKIs). Off-target cytotoxicity, which generally has been considered a major limitation for clinical use of immunotoxins, may be reduced by utilizing a type 1 ribosome-inactivating protein (RIP) [12]. In contrast to highly potent toxins such as ricin, Pseudomonas exotoxin (PE) and diphtheria toxin, type 1 RIPs lack a translocation domain which transports the toxin from endosomes into the cytosol [13]. Thus, a technology which allows improved endo/lysosomal release of these agents has the potential to increase specific cytotoxicity provided by type 1 RIP-based immunotoxins [14]. Photochemical internalization (PCI) is a technology which causes cytosolic release of drugs entrapped in endocytic vesicles $[15,16]$. PCI is based on an amphiphilic photosensitizer (PS) which accumulates in the membranes of endosomes and lysosomes. Light exposure with appropriate wavelengths, excites the PS and initiates the production of reactive oxygen species (ROS) which in turn destroys the endo/lysosomal membrane [17]. PCI of several drugs has been proven as an effective treatment modality for cancer in vivo $[18,19,20,21]$ and ongoing clinical studies on PCI are showing highly promising results (www.clinicaltrials. gov; NCT01606566, NCT01872923, NCT01900158).

In the present study we evaluated PCI of the HER2-targeted single chain antibody-based recombinant immunotoxin MH3-B1/rGel in three ovarian cancer cell lines, generally resistant to HER2-targeted therapy, and also on ovarian cancer xenografts in athymic mice. These results indicate PCI of HER2-targeted toxins to be a promising treatment modality for HER2 overexpressing ovarian cancer and warrants future evaluation in preclinical models.

\section{RESULTS}

\section{HER2 expression among the cell lines}

The HER2 expression level in the 4 selected human cancer cell lines was found to vary in agreement with other reports. Both SK-BR-3 and SKOV-3 were found to be HER2-high expressing and the HER2 level in SK-BR-3 was indicated higher than observed in the SKOV-3 cells [10, 28] (Fig. 1A). An intermediate HER2 expression was found in the HOC-7 cell line [29] (Fig. 1A) while MDAMB-468 was indicated as HER2-low [30, 10] (Fig. 1A).
A weak HER2 band was also detected on overexposed western blots of Nu-Tu-19 cells (rat orgin) (Fig. 1A). However, the apparent weak HER2 expression in NuTu-19 cells may be due to poor recognition of HER2 rat antigen by the antibody (antibody against human HER2) and comparison of HER2 level between $\mathrm{Nu}-\mathrm{Tu}-19$ and the human cell lines is therefore not possible.

\section{Sensitivity of SK-BR-3 and SKOV-3 cells to HER2-targeted therapeutics}

In this study, the responsiveness to PCI of MH3-B1/ rGel was primarily evaluated in 2 HER2 overexpressing cell lines; the human breast cancer cell line SK-BR-3 and the human ovarian cancer cell line SKOV-3 (Fig. 1A). Subjecting the 2 cell lines to a $72 \mathrm{hrs}$ incubation of the HER2-targeted immunotoxin $\mathrm{MH} 3-\mathrm{B} 1 / \mathrm{rGel}$ revealed a low $\mathrm{TI}_{50}$ of $\sim 2.4$ in the SKOV-3 cell line, compared to the $\mathrm{TI}_{50}$ of $\sim 136$ in SK-BR-3 cells (Fig. 1B and 1C). The lack of response to $\mathrm{MH} 3-\mathrm{B} 1 / \mathrm{rGel}$ in $\mathrm{SKOV}-3$ cells was also reflected in the response to the $\mathrm{scFv}$ targeting moiety MH3-B1 which reduced the viability by $\sim 20 \%$ in SKOV3 cells compared to $\sim 60 \%$ in SK-BR-3 cells following a $72 \mathrm{hrs}$ incubation at a $10 \mu \mathrm{M}$ concentration (Fig. 1D). The SKOV-3 cells were in addition found resistant to the HER2-targeted mAb trastuzumab (Fig. 1E), in agreement with previous reports $[29,31]$ while the SK-BR-3 cells responded well with an $\mathrm{LD}_{50}$ of $\sim 100 \mathrm{nM}$. The present results therefore indicate that SKOV-3 cells are generally resistant to HER2-targeted antibody-based therapy.

\section{Uptake and cellular localization of Alexa488- MH3-B1/rGel in SK-BR-3 and SKOV-3 cells}

PCI is a method for cytosolic release of drugs entrapped in endosomes and lysosomes. PCI in vitro is usually performed by a 1-18 hrs incubation of the macromolecule of interest prior to light exposure $[32,17]$. This relatively short incubation time of the macromolecule is utilized to avoid strong influence of lysosomal degradation on the PCI outcome. In the present in vitro protocol, a $4 \mathrm{hrs}$ pulse of $2 \mathrm{nM} \mathrm{MH3-B1/rGel} \mathrm{was}$ used prior to the light exposure. Since the intracellular trafficking of $\mathrm{MH} 3-\mathrm{B} 1 / \mathrm{rGel}$ in the post-treatment period is expected to influence on the therapeutic effect, a cytotoxicity evaluation was performed $72 \mathrm{hrs}$ after the $4 \mathrm{hrs}$ pulse of MH3-B1/rGel to verify that SKOV-3 cells were resistant to $\mathrm{MH} 3-\mathrm{B} 1 / \mathrm{rGel}$ also after a $4 \mathrm{hrs}$ treatment (Fig. 2A and 2B). The TI's after $4 \mathrm{hrs}$ treatment were found to be higher in both cell lines compared to that after 72 hrs treatment. However, the SKOV-3 cells were found to be relatively less sensitive to the treatment as e.g. $2 \mathrm{nM}$ MH3-B1/rGel reduced cell viability by $\sim 35 \%$ in SK-BR-3 cells (Fig. 2B), but did not induce detectable cytotoxicity in the SKOV-3 cell line (Fig. 2A). Calculating the TI at 
A

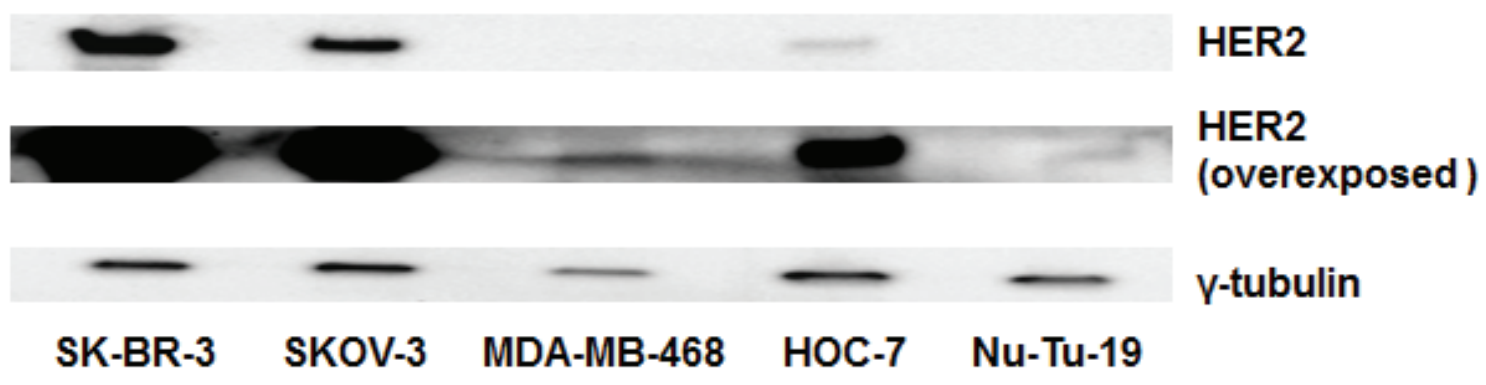

B

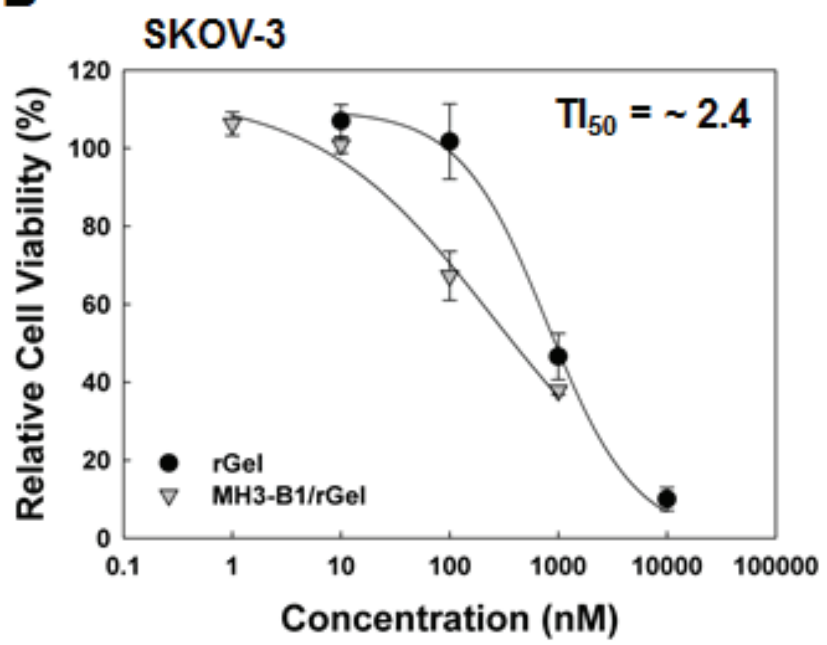

C

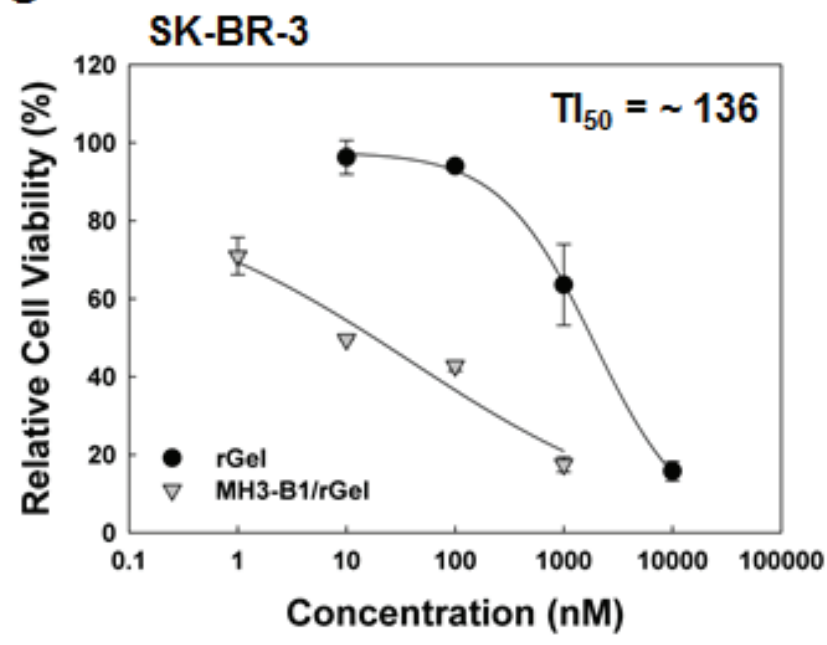

D

$\mathbf{E}$
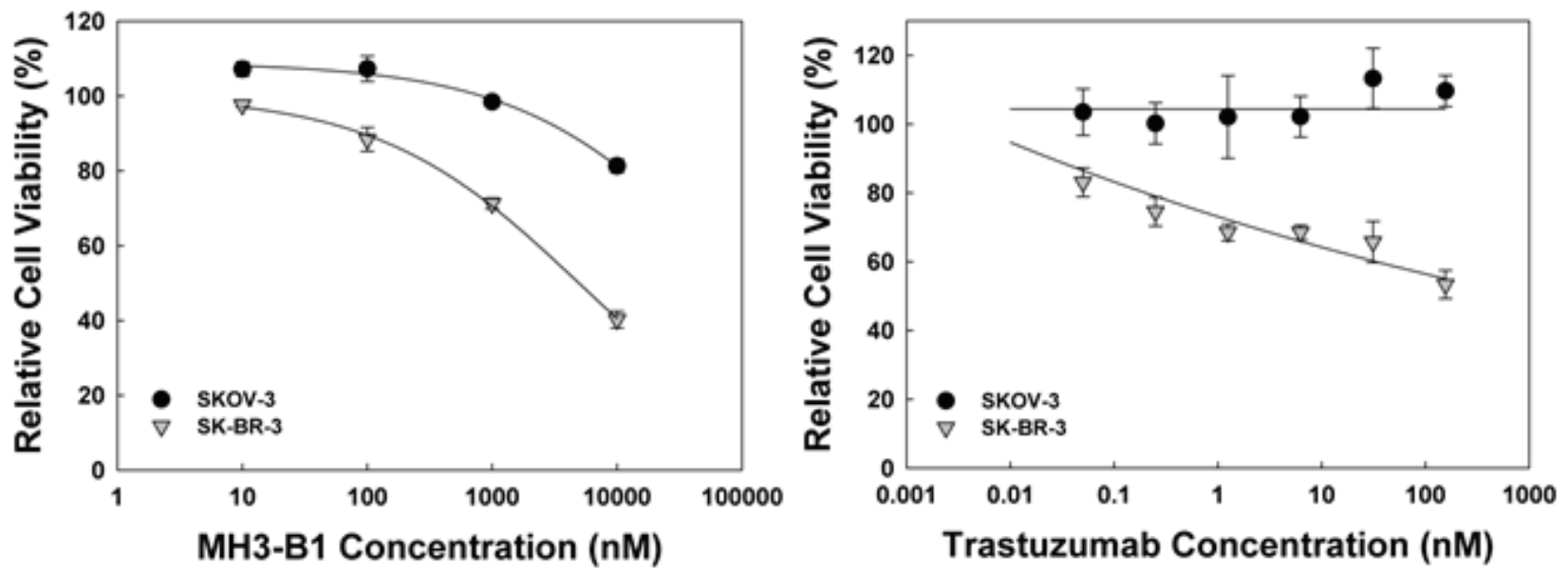

Figure 1: Cellular HER2 expression and cytotoxicity of HER2-targeted compounds. (A). Western blot showing basal HER2 expression in SK-BR-3, SKOV-3, MDA-MB-468, HOC-7 and Nu-Tu-19 cells, representative blot of two experiments. Relative cell viability (MTT) of SKOV-3 and SK-BR-3 cells following 72 hrs incubation with MH3-B1/rGel and rGel (B and C), MH3-B1 (D) and trastuzumab (E), representative sigmoidal curves of three experiments (fit model: $\left.\mathrm{a} /\left(1+\exp \left(-\left(\mathrm{x}-\mathrm{x}_{0}\right) / \mathrm{b}\right)\right)\right)$, error bars $=\mathrm{SD}$. 


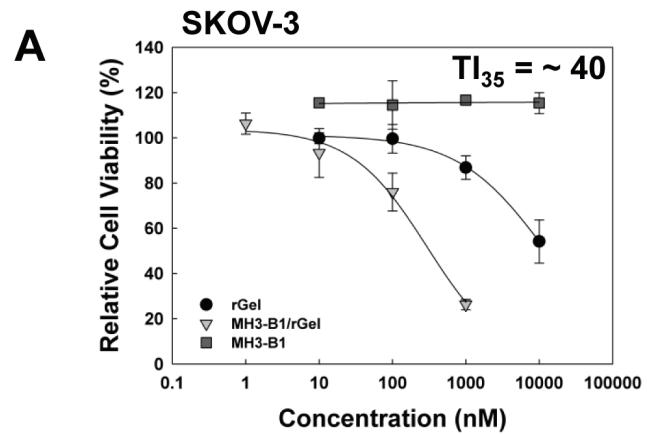

C

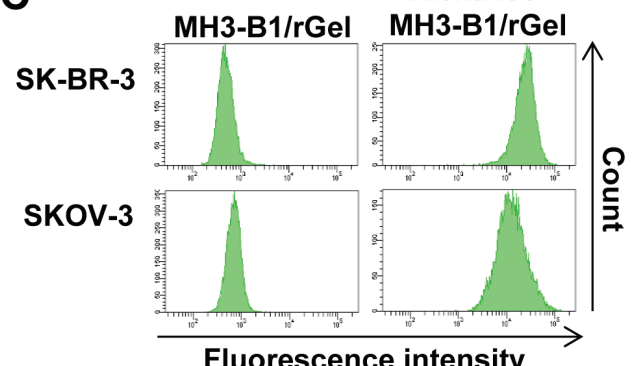

E
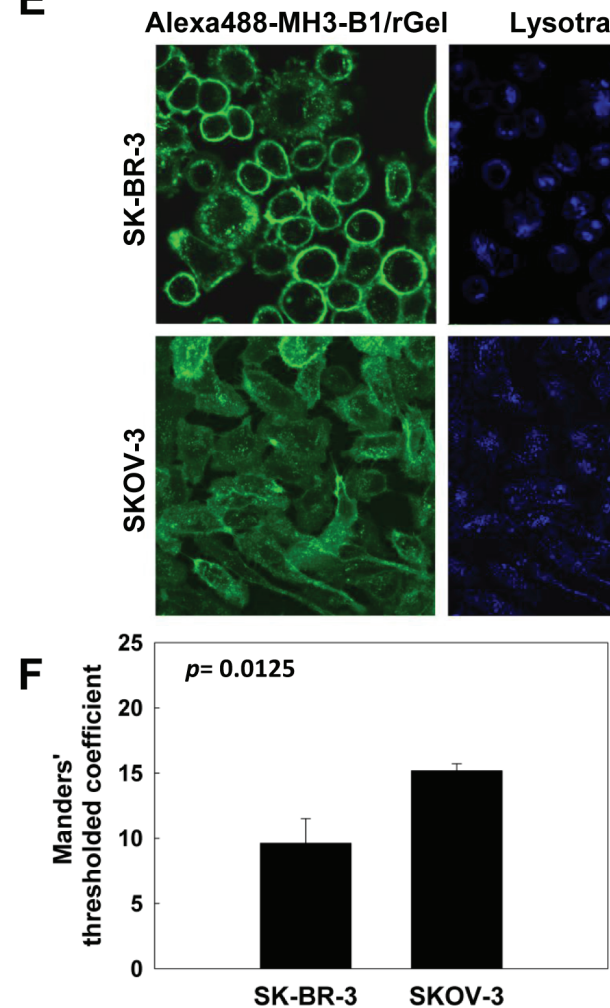

B

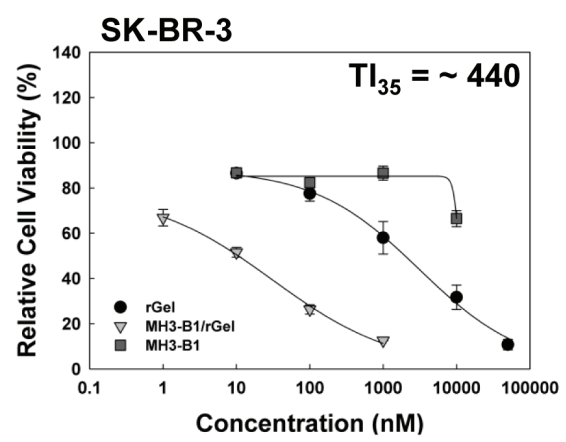

D
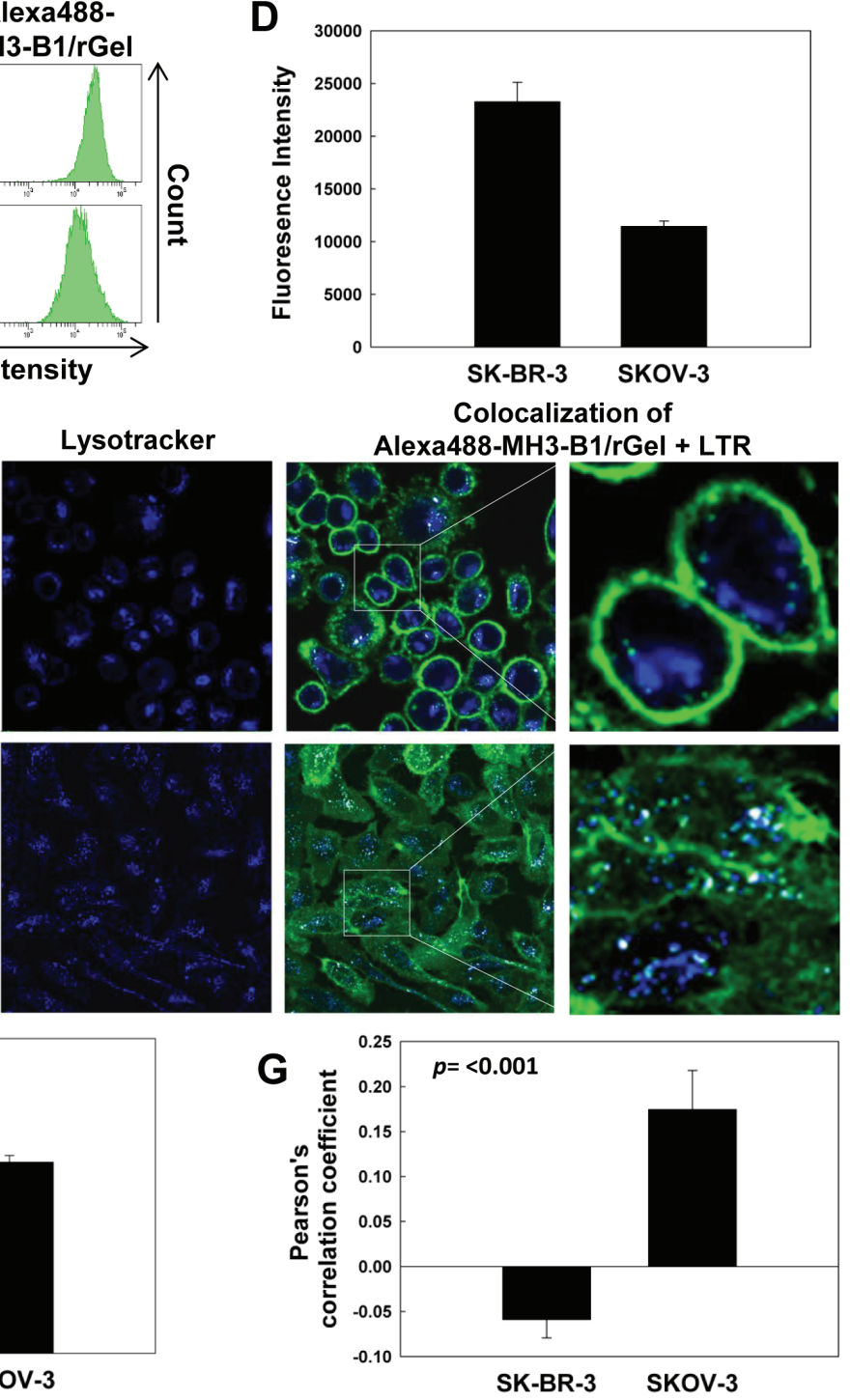

Figure 2: Cytotoxicity, uptake and cellular localization of MH3-B1/rGel after 4 hrs incubation. Relative cell viability (MTT) of SK-BR-3 (A) and SKOV-3 (B) following 4 hrs incubation with MH3-B1/rGel, rGel and MH3-B1, representative sigmoidal

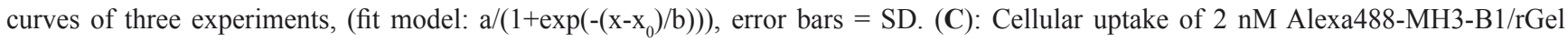
following 4 hrs incubation in SK-BR-3 and SKOV-3 cells, representative flow cytometry charts of three experiments. (D): Total cellular Alexa488-MH3-B1/rGel fluorescence, average of three experiments, error bars = SE. (E): SK-BR-3 and SKOV-3 cells following 4 hrs incubation of $2 \mathrm{nM}$ Alexa-488-MH3-B1/rGel. Alexa488-MH3-B1/rGel (green), LTR (blue) and colocalization of the two (white). The confocal micrographs are representative of three independent experiments. The colocalization of Alexa488-MH3-B1/rGel with LTR was calculated by the Manders' thresholded coefficient from the total cellular accumulation measured (F) and the Pearson's correlation coefficient was used to calculate the correlation between Alexa488-MH3-B1/rGel and LTR based on fluorescence intensities/pixel (G), F and $\mathrm{G}$ shows average of three experiments, error bars $=\mathrm{SE}$. 
$\mathrm{IC}_{35}$ of $\mathrm{MH} 3-\mathrm{B} 1 / \mathrm{rGel}$ vs. rGel $\left(\mathrm{TI}_{35}\right)$ revealed an $\sim 11-$ fold higher $\mathrm{TI}_{35}$ in SK-BR-3 cells compared to SKOV-3 cells after 4 hrs treatment with MH3-B1/rGel. SKOV-3 cells were therefore found resistant to $\mathrm{MH} 3-\mathrm{B} 1 / \mathrm{rGel}$ also when administrated for $4 \mathrm{hrs}$ compared to SK-BR-3 cells. Four hrs incubation of MH3-B1 (without rGel) did not induce any significant cytotoxicity in any of the cell lines, indicating $\mathrm{MH} 3-\mathrm{B} 1 / \mathrm{rGel}-$ mediated toxicity to be generated through ribosomal inhibition (Fig. 2A and 2B).

$\mathrm{MH} 3-\mathrm{B} 1 / \mathrm{rGel}$ primarily exerts its intracellular action by inducing inhibition of protein synthesis. The mechanism of MH3-B1/rGel resistance in the SKOV-3 cell line could be due to differences in overall uptake and/ or intracellular MH3-B1/rGel localization and trafficking compared to SK-BR-3 cells. Subjecting SK-BR-3 and SKOV-3 cells to a 4 hrs incubation of $2 \mathrm{nM}$ Alexa488labeled MH3-B1/rGel revealed a 2 -fold higher Alexa488MH3-B1/rGel uptake in SK-BR-3 cells compared to SKOV-3 cells (Fig. 2C and 2D). However, this 2-fold

\section{A SK-BR-3}

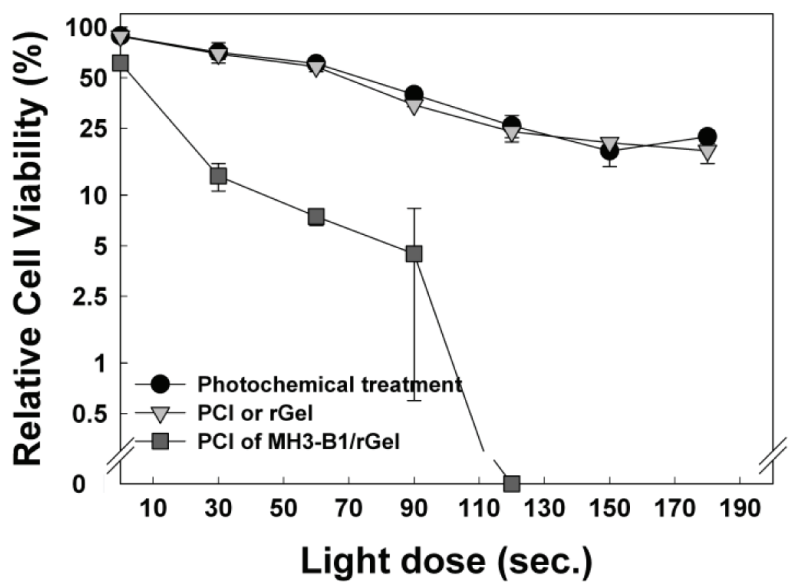

C MDA-MB-468

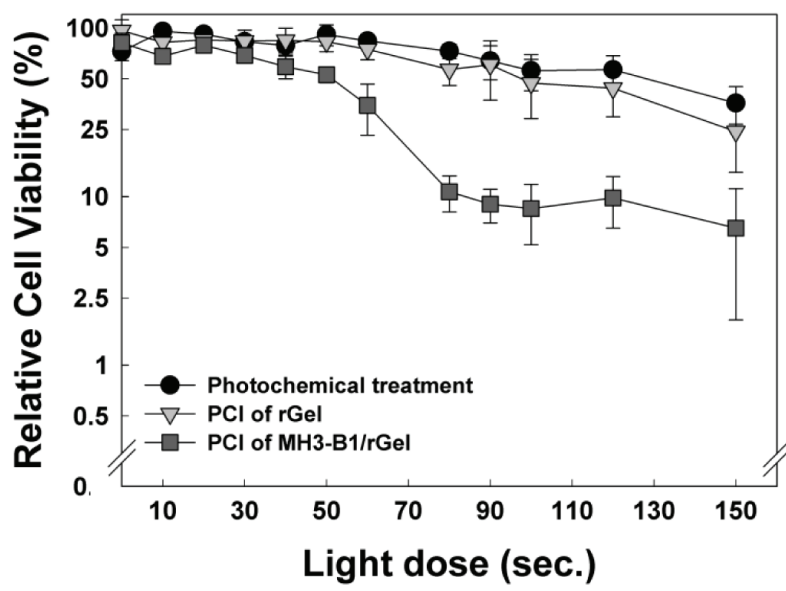

difference could only partly explain the $\sim 11$-fold higher $\mathrm{TI}_{35}$ in SK-BR-3 cells following a $4 \mathrm{hrs}$ MH3-B1/rGel incubation (Fig. 2A and 2B).

The MH3-B1/rGel construct must eventually translocate from endosomes and/or lysosomes into the cytosol to exert its action on the ribosomes and avoid lysosomal degradation [12]. Thus, differences in distribution of the targeting toxin in endocytic vesicles between SKOV-3 and SK-BR-3 cells could explain the difference in $\mathrm{MH} 3-\mathrm{B} 1 / \mathrm{rGel}$ sensitivity. Intracellular localization of Alexa488-labeled MH3-B1/rGel was detected by confocal microscopy which confirmed both binding of the immunotoxin to the plasma membrane and cellular internalization to endocytic compartments in both cell lines (Fig. 2E). The association of Alexa488$\mathrm{MH} 3-\mathrm{B} 1 / \mathrm{rGel}$ to the plasma membrane appeared much stronger in the SK-BR-3 cells than in the SKOV-3 cells. However, this visual appearance may at least partly be due to the more rounded up morphology of the SK-BR-3
B

\section{SKOV-3}

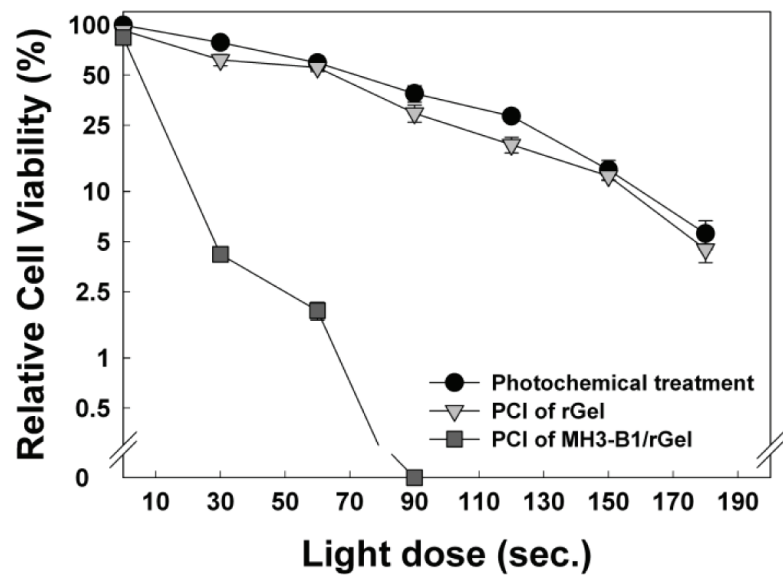

D

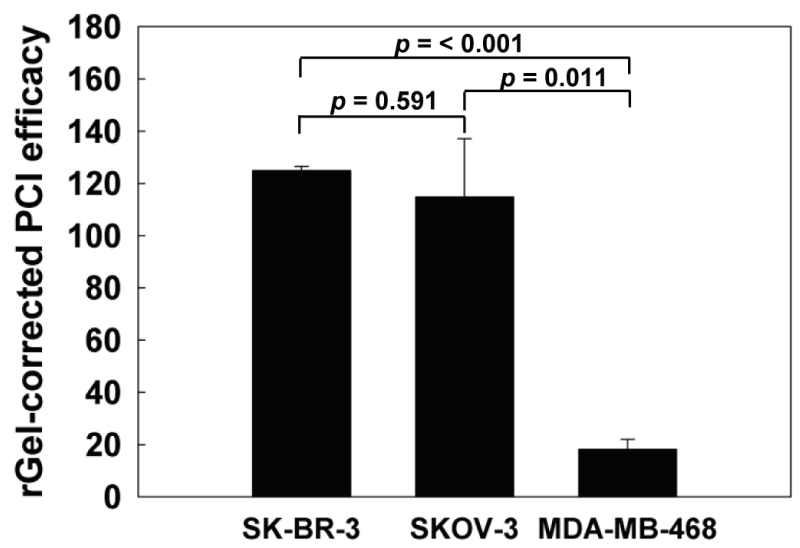

Figure 3: PCI efficacy of MH3-B1/rGel in SK-BR-3 and SKOV-3 cells. Relative cell viability (MTT) of SK-BR-3 (A), SKOV-3 (B) and MDA-MB-468 (C) cells after PCI of $2 \mathrm{nM} \mathrm{MH3-B1/rGel} \mathrm{(incubated} \mathrm{for} 4 \mathrm{hrs}$ ), representative curves from three experiments, error bars $=$ SD. (D): rGel-corrected PCI efficacy, average of three experiments, in SK-BR-3, SKOV-3 and MDA-MB-468 cells. 
cells. Diffuse fluorescence was, in addition, observed in the cytoplasm of SKOV-3 cells. The thin morphology of SKOV-3 cells $(\sim 1.5 \mu \mathrm{m})$, together with the axial resolution of the microscope $(0.56 \mu \mathrm{m})$ and differences in the optimal plane of microscopy between cells in the same micrograph was, however, found as the reason for this diffuse fluorescence which was concluded as noise from the plasma membrane. A significantly higher fraction (15.2\% vs. $9.6 \%$ ) of Alexa488-MH3-B1/rGel was found to colocalize with LTR in SKOV-3 cells than in SK-BR-3 cells $(p=0.0125)$ (Fig. 2F). The distribution of Alexa488MH3-B1/rGel correlated also better with the distribution of LTR as revealed by the Pearson's correlation coefficient of $0.17( \pm 0.04)$ in SKOV-3 cells as compared to -0.059 $( \pm 0.02)$ in the SK-BR-3 cells $(p<0.001)$ (Fig. 2G). A higher distribution of $\mathrm{MH} 3-\mathrm{B} 1 / \mathrm{rGel}$ in acidic endocytic vesicles in SKOV-3 cells indicates a higher hydrolytic degradation of the immunotoxin in the vesicles of these cells compared to SK-BR-3 cells. This hydrolysis may take place in all acidic endocytic vesicles including both endosomes and lysosomes [33, 34]. Attempts have been made to remove plasma membrane associated fusion toxin in order to quantitatively measure intracellular fusion toxin. Such a method would make it possible to compare the impact of e.g. a lysosomotropic agent on MH3-B1/ rGel degradation in the two cell lines. However, the high plasma membrane association of $\mathrm{MH} 3-\mathrm{B} 1 / \mathrm{rGel}$ in these two cell lines makes this a difficult task since only small contamination from the plasma membrane is likely to influence strongly on this suggested experiment. Thus, the increased distribution of Alexa488-MH3-B1/rGel in acidic vesicles in the SKOV-3 cell line together with the higher overall uptake in the SK-BR-3 cells may explain the lower sensitivity to $\mathrm{MH} 3-\mathrm{B} 1 / \mathrm{rGel}$ in the SKOV-3 cells compared to SK-BR-3 cells.

\section{PCI of MH3-B1/rGel in SK-BR-3 and SKOV-3 cells}

Since high hydrolytic degradation was indicated as a potential mechanistic cause of the low MH3-B1/rGel sensitivity in the SKOV-3 cells, we hypothesized that PCI may be useful in addressing this mechanism of resistance. Studies combining PCI and MH3-B1/rGel demonstrated highly effective cytotoxicity against SKOV-3 cells and appeared to reduce the cell viability to the same extent as observed for the SK-BR-3 cells (Fig. 3A and 3B). PCI of $\mathrm{MH} 3-\mathrm{B} 1 / \mathrm{rGel}$ was also indicated as HER2 selective when compared to PCI of non-targeted rGel (Fig. 3A and 3B) and also when comparing the PCI data for SK-BR-3 and SKOV-3 cells with those obtained with the HER2 low expressing cell line MDA-MB-468 (Fig. 3A-3C). The efficacy of PCI of MH3-B1/rGel has recently been shown to correlate well with HER2 expression [23]. PCI efficacy may be established by comparing the light dose needed to obtain $\mathrm{LD}_{50}$ with PCI with that of the photochemical treatment (PS and light) and correct the calculation for cellular differences in sensitivity to the non-targeted toxin (as described in Materials and Methods, [23]). The PCI efficacy corrected for rGel-sensitivity in the two cell lines revealed similar efficacy of PCI of $\mathrm{MH} 3-\mathrm{B} 1 / \mathrm{rGel}$ in the resistant SKOV-3 cells as in the SK-BR-3 cells $(p>0.05)$ (Fig. 3D). The rGel-corrected PCI efficacy in MDAMB-468 cells was, however, found to be 6.8- and 6.3-fold reduced compared to that in SK-BR-3 and SKOV-3 cells respectively (Fig. 3D).

\section{PCI of MH3-B1/rGel in HOC-7 and NuTu-19 cells}

Ovarian cancer is generally known to have low sensitivity to HER2-targeted therapeutics despite strong HER2 expression [3, 5]. The high PCI-induced efficacy of $\mathrm{MH} 3-\mathrm{B} 1 / \mathrm{rGel}$ in SKOV-3 cells was therefore also tested in the ovarian cancer cell lines HOC-7 and NuTu19. HOC-7 cells were found resistant to trastuzumab and $\mathrm{MH} 3-\mathrm{B} 1 / \mathrm{rGel}$ to a comparable level as detected in SKOV3 cells (Fig. 4A and 4B, Fig. 1B and 1E). Accordingly, NuTu-19 cells have previously been reported to not respond to trastuzumab [35] and were also found resistant to $\mathrm{MH} 3-\mathrm{B} 1 / \mathrm{rGel}$ (Fig. 4C). PCI was shown to increase the effect of MH3-B1/rGel significantly in HOC-7 and NuTu-19 cells (Fig. 4D and 4E), indicating that MH3-B1/ rGel is accumulating specifically in both cell lines although the therapeutic specificity is more strongly seen after activation by PCI. These results are in accordance with those seen in the SKOV-3 cells (Fig. 3B). HER2 expression in HOC-7 cells was, however, much lower than observed for SKOV-3 cells (Fig. 1A).

\section{PCI of MH3-B1/rGel on SKOV-3 xenografts in vivo}

The high efficacy of PCI of MH3-B1/rGel in the $\mathrm{MH} 3-\mathrm{B} 1 / \mathrm{rGel}$ resistant $\mathrm{SKOV}-3$ cells was further evaluated on SKOV-3 subcutaneous xenografts in athymic mice. This is a relatively slow growing tumor model and the mean time to reach the endpoint of $800 \mathrm{~mm}^{3}$ from a treatment volume of $\sim 100 \mathrm{~mm}^{3}$ was 43.4 days (Fig. $6 \mathrm{D})$. The photochemical treatment induced edema and accurate measurements of tumors were therefore difficult to obtain the first $\sim 2$ weeks after treatment. Early effects on tumor growth following the different treatments were assessed on day 16 since this was the first day without any detectable edema in any of the animals. Comparing the size of all tumors at day 16 revealed significantly smaller tumors in the PCI group compared to the control groups receiving either $\mathrm{MH} 3-\mathrm{B} 1 / \mathrm{rGel}$, photochemical treatment or no treatment (Fig. 5A and 5C). No significant difference was found between the no treatment group and the groups receiving $\mathrm{MH} 3-\mathrm{B} 1 / \mathrm{rGel}$ or photochemical treatment as 

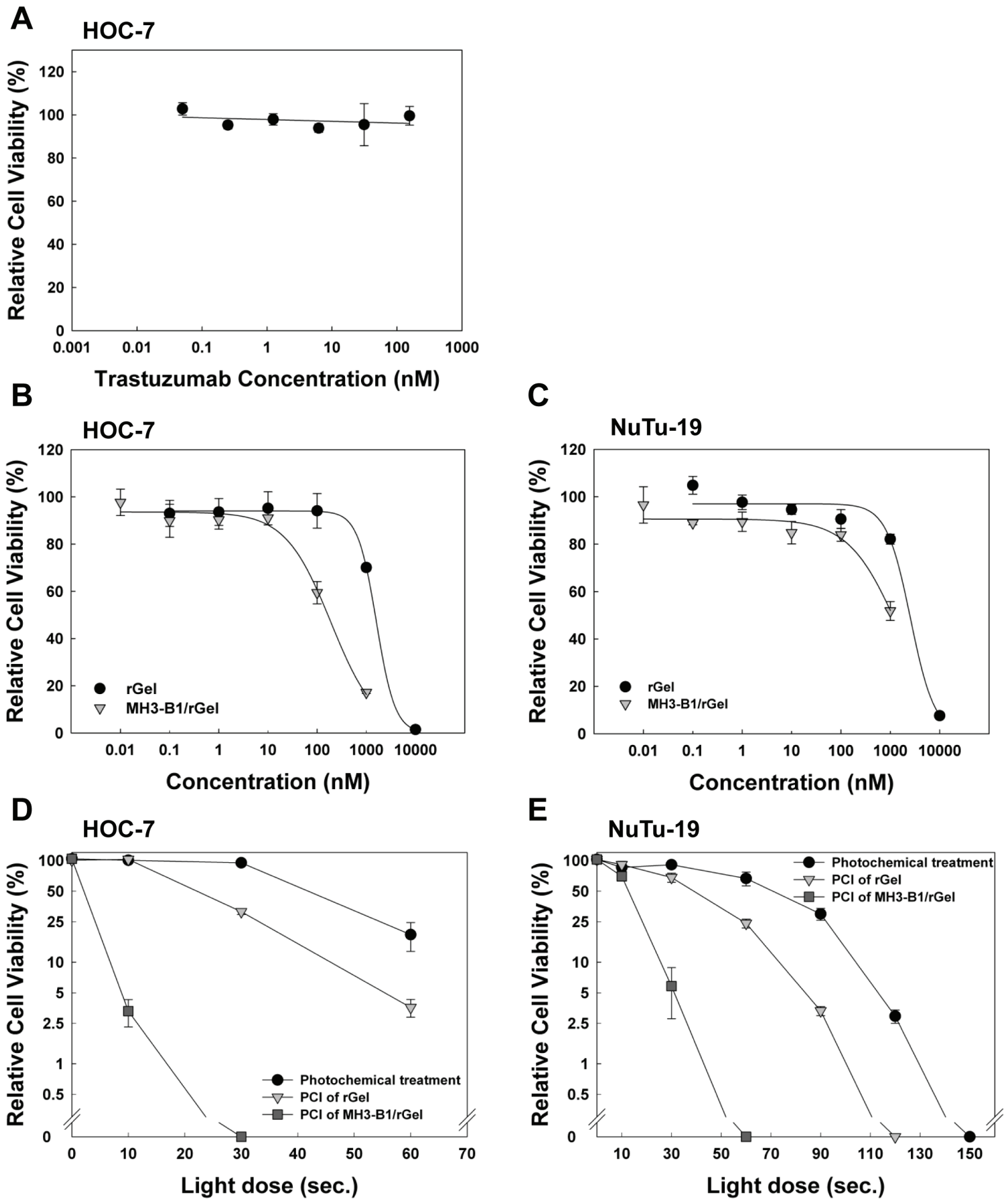

Figure 4: PCI of MH3-B1/rGel in HOC-7 and NuTu-19 cells. Relative cell viability (MTT) of HOC-7 cells following 72 hrs incubation with trastuzumab (A) and MH3-B1/rGel and rGel (B). Relative cell viability (MTT) of NuTu-19 cells following 72 hrs incubation with MH3-B1/rGel and $\mathrm{rGel}(\mathbf{C})$. Representative sigmoidal curves of three experiments (fit model: $\mathrm{a} /\left(1+\mathrm{exp}\left(-\left(\mathrm{x}-\mathrm{x}_{0}\right) / \mathrm{b}\right)\right)$, error bars $=$ SD. (D) and (E) shows relative cell viability (MTT) of HOC-7 and NuTu-19 cells after PCI of 2nM MH3-B1/rGel (incubated for 4 hrs), representative curves of three experiments, error bars $=\mathrm{SD}$. 


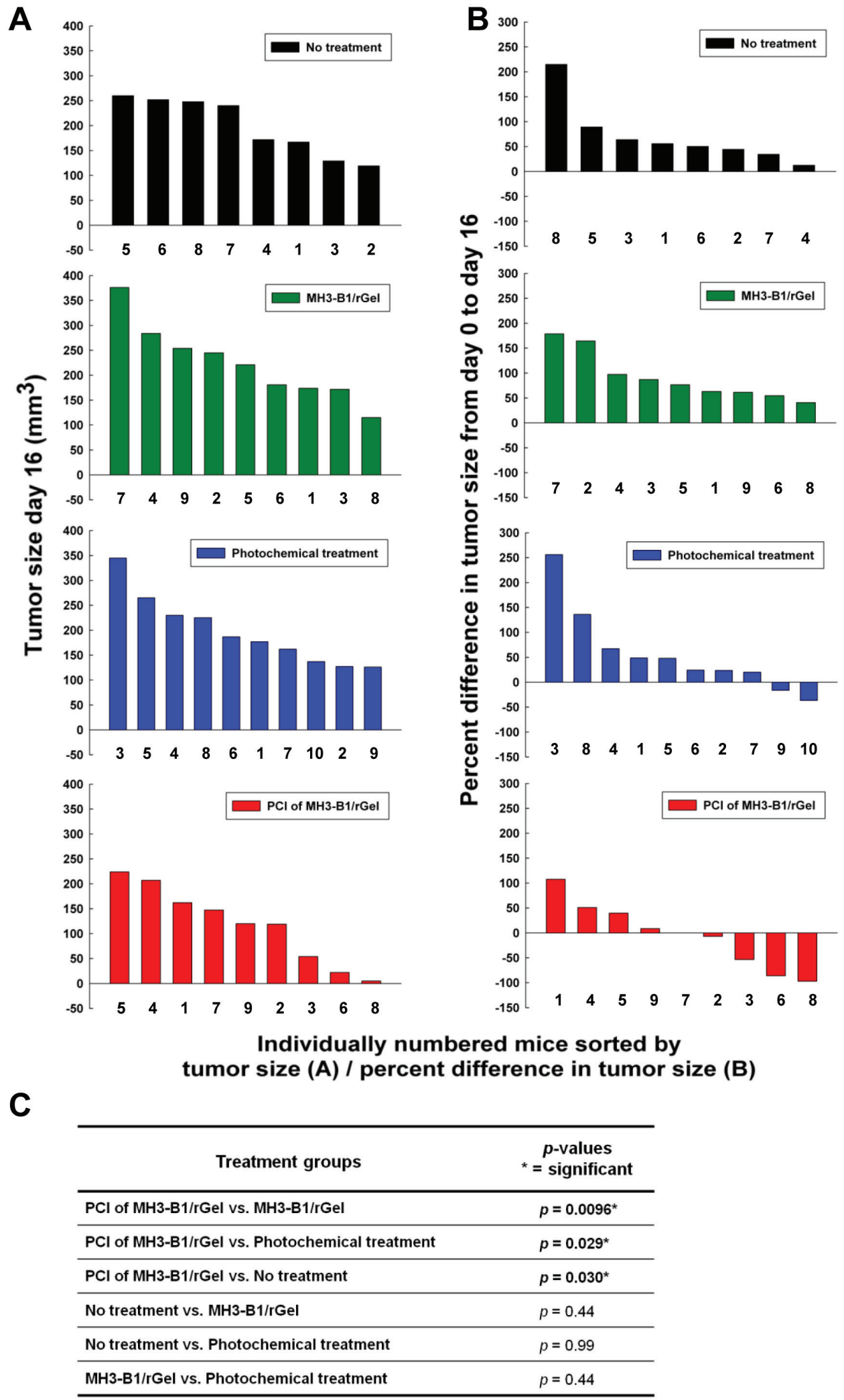

Figure 5: Tumor size after PCI of MH3-B1/rGel in SKOV-3 xenografts. The bars show the measured tumor size at day 16 for each animal in the four treatment groups (A) and the percent change in tumor size at day 16 calculated from the measured tumor size at treatment day (day 0) for each animal in the four treatment groups $(\mathbf{B})$. Calculated $p$-values representing statistical differences in tumor size between the treatment groups at day 16 post treatment $(\mathbf{C})$. 
monotherapies. Neither was there any difference in tumor size between the group receiving $\mathrm{MH} 3-\mathrm{B} 1 / \mathrm{rGel}$ and the photochemical treatment group at day 16 (Fig. 5A and 5C).

The percent change in tumor size at day 16 compared to the tumor size measured at day 0 for each animal, revealed a stronger inhibition of tumor growth in the PCI group than in the control groups. All the animals in the MH3-B1/rGel monotherapy and no treatment group showed an increase in tumor volume at day 16 compared to day 0 (Fig. 5B). However, the tumors subjected to the photochemical treatment (PS and light) showed an overall lower growth and even some reduction in tumor volume. The volume of the tumors in the PCI group was even smaller than those only subjected to the photochemical treatment (PS and light) and a higher number of tumors showed a reduced tumor volume.

Although statistically not significant, a treatment response of SKOV-3 tumors following PCI of MH3-B1/ rGel was also indicated in Kaplan-Meier plots between day 38 and 50 post light exposure (Fig. 6A). At day 50, $44 \%$ of the animals that received PCI of MH3-B1/rGel had tumors with a size $<800 \mathrm{~mm}^{3}$ compared to $20 \%$ in the photochemical treatment group, whereas all the tumors in the no treatment group and the group that received $\mathrm{MH} 3-\mathrm{B} 1 / \mathrm{rGel}$ monotherapy had reached the end point of $800 \mathrm{~mm}^{3}$ (Fig. 6A). Measurements of tumor growth delay confirmed treatment response in the PCI group compared to the control groups also at day 20, 30 and 40 post-treatment as illustrated in Fig. 6C. The mean time to reach a tumor volume of $800 \mathrm{~mm}^{3}$ is presented in Fig. $6 \mathrm{D}$ and growth curves is presented in S1. No correlation was found between the actual tumor size at the day of treatment and treatment response.

The effect of the applied PCI treatment was smaller than expected from the encouraging in vitro data presented here in addition to previous in vivo reports on PCI of other targeting toxins $[20,21]$. The $48 \mathrm{hrs}$ interval between MH3-B1/rGel administration and light exposure used in this study was based on MH3-B1/rGel accumulation
A

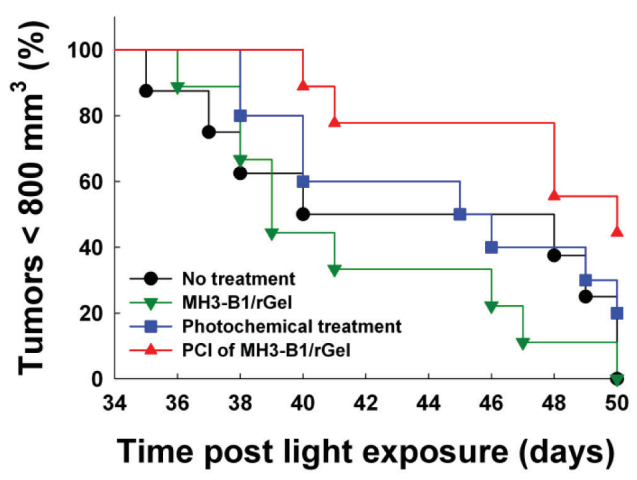

B

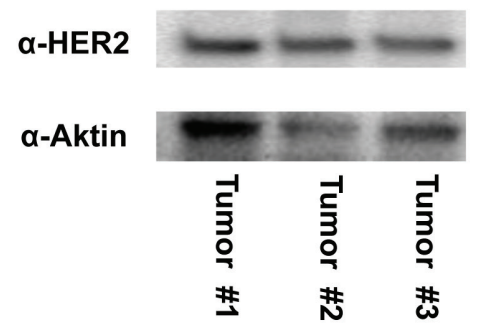

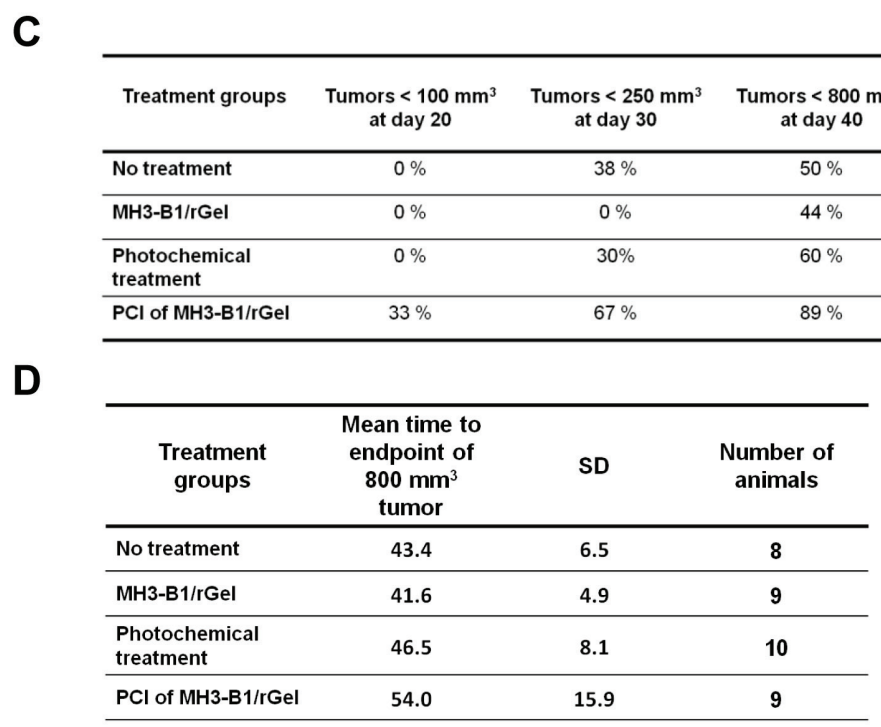

Figure 6: Treatment response following PCI of MH3-B1/rGel in SKOV-3 xenografts. Kaplan Meyer plot illustrating response from day 34-50 in the four treatment groups (A). Tumor volume end point $=800 \mathrm{~mm}^{3}$. Western blot of HER2 in three SKOV-3 tumors (B). Percent of animals bearing tumors $<100 \mathrm{~mm}^{3}$ at day $20,<250 \mathrm{~mm}^{3}$ at day 30 and $<800 \mathrm{~mm}^{3}$ at day 40 post light exposure in the four treatment groups (C). Average time to reach the endpoint of $800 \mathrm{~mm}^{3}$ tumor volume in the four treatment groups (D). 
studies in BT474 M1 tumors [9] and this interval was decreased to $24 \mathrm{hrs}$ to study if this would increase the treatment response. No increase in efficacy was, however, detected by reducing the MH3-B1/rGel-to-light interval to 24 hrs (data not shown). Western blots of HER2 in three SKOV-3 tumors verified high expression of HER2 in these xenografts (Fig. 6B).

\section{Tumor accumulation of MH3-B1/rGel in SKOV-3 xenografts}

The amount of MH3-B1/rGel localized to the tumor at the time of light exposure (48 hrs post injection) was assessed by western blotting of tumor lysates. These western analysis failed, however, to demonstrate the presence of the fusion construct in the tumors (results
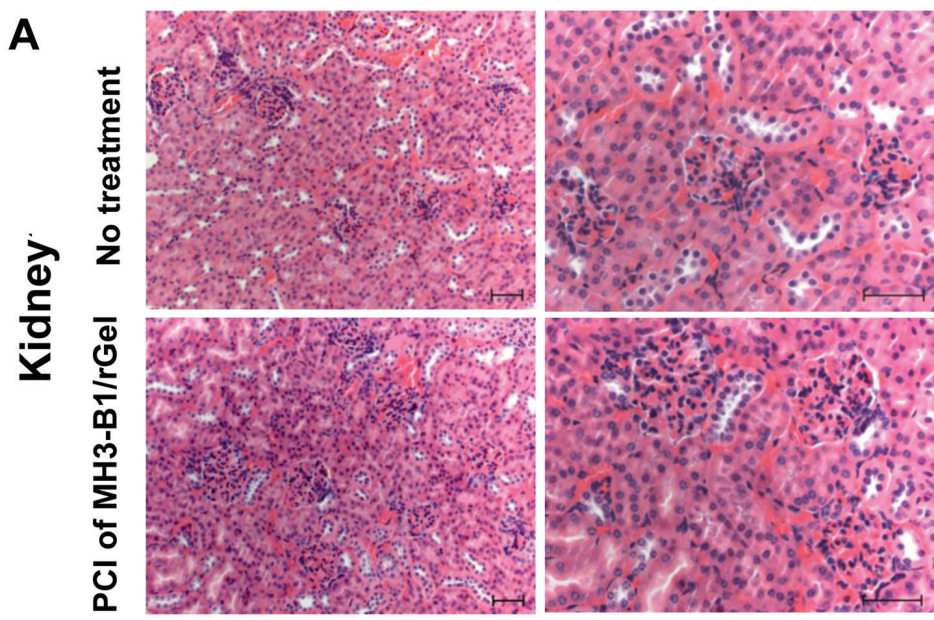

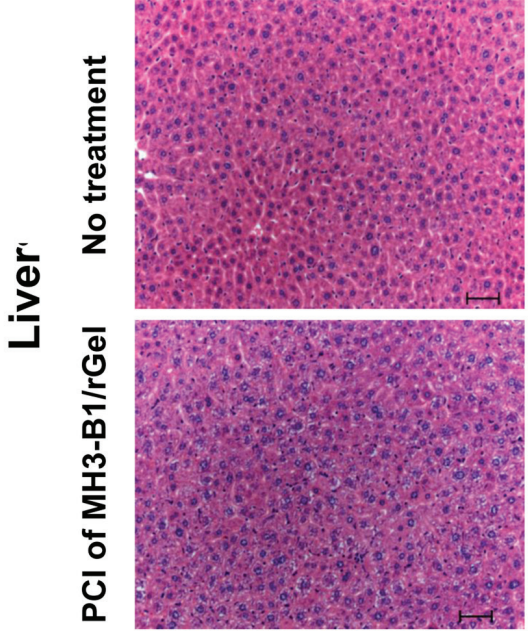

$10 x$

B

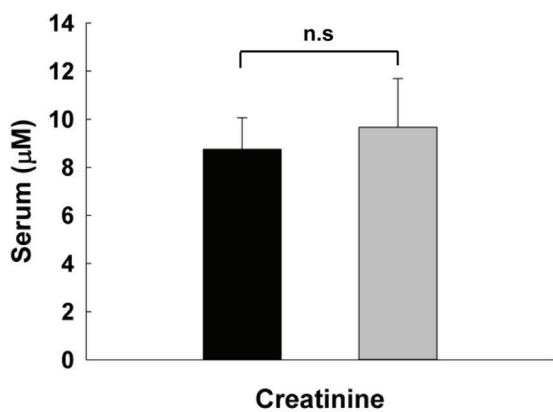

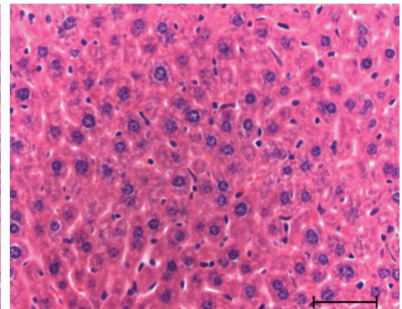

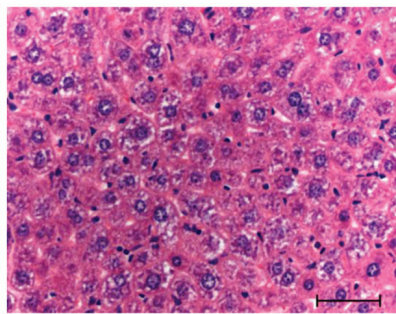

$20 x$

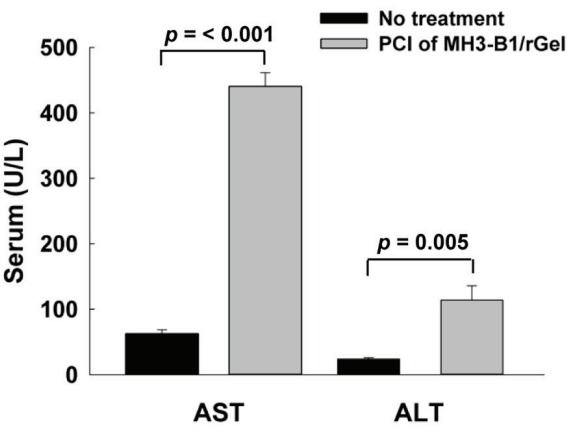

Figure 7: Adverse effects following PCI of MH3-B1/rGel in SKOV-3 xenografts. H\&E staining of kidney and liver tissue in untreated and PCI of MH3-B1/rGel treated animals 24 hrs post light exposure (A). Bar: $50 \mu \mathrm{m}$. Serum levels of creatinine, AST and ALT in untreated and PCI of MH3-B1/rGel treated animals 24 hrs post light exposure (B). 
not shown). A standard of MH3-B1/rGel indicated $0.5 \mathrm{ng}$ $\mathrm{MH} 3-\mathrm{B} 1 / \mathrm{rGel}$ as the detection limit for $\mathrm{MH} 3-\mathrm{B} 1 / \mathrm{rGel}$ on a western blot which would correspond to $208 \mathrm{ng}(3.78$ $\left.\mathrm{x} 10^{-12} \mathrm{~mol}\right) \mathrm{MH} 3-\mathrm{B} 1 / \mathrm{rGel} / \mathrm{g}$ tumor tissue in a $0.2 \mathrm{~g}$ tumor. The amount of MH3-B1/rGel localized to the tumors at the time of light exposure with the present protocol was therefore less than $3.78 \times 10^{-12}$ moles/g tumor tissue.

\section{Adverse effects of the treatment}

Damage to the liver and kidneys of mice was evaluated $24 \mathrm{hrs}$ after the PCI treatment. No adverse effects on the kidneys were noted by histopathology and also by measuring the serum levels of creatinine, an indicator of renal function (Fig. 7A and 7B). Hepatocytes, however, showed their central nuclei surrounded by many vacuoles in the cytoplasm (Fig. 7A), a typical morphological alteration indicating reversible degeneration. This is consistent with the results which demonstrated a significant increase in serum levels of AST and ALT (Fig. 7B) in the PCI-treated animals. Such reversible hepatic degeneration indicates that the PCI treatment may induce a slight liver toxicity, but with no reduction in the daily activities as well as body weight of the treated mice. In the skin, erythema for up to 2 weeks was detected at the illuminated area, while light alone (without PS) as a control did not cause such effect. In addition, a small wound in the treated area was observed in 3 out of 10 mice, but leaving no scarring. Thus, generally, PCI of MH3-B1/rGel was considered as a tolerable treatment.

\section{DISCUSSION}

In the present study, we have utilized the intracellular drug delivery technology PCI to potentiate the cytotoxicity of the HER2-targeted recombinant immunotoxin, MH3-B1/rGel in HER2 overexpressing ovarian cancer cell lines. Ovarian cancer is the most lethal of all gynecological cancers with a 5 year survival of only $44.2 \%$ [36]. Up to $35 \%$ of ovarian cancers have been reported as HER2-positive [37, 6, 7]. HER2-targeted antibodies and molecular inhibitors have, however, failed to demonstrate significant clinical benefit as monotherapy [38] and the prognostic value of HER2 expression in ovarian cancer is controversial [38]. The aim of this study was to utilize HER2 as the delivery portal for MH3-B1/ rGel to endocytic vesicles in the ovarian cancer cell line SKOV-3. PCI-induced cytosolic translocation of MH3-B1/ rGel should further facilitate ribosomal binding, inhibition of protein synthesis and induction of cell death. The HER2-positive breast cancer cell line SK-BR-3, recently reported as highly sensitive to PCI of MH3-B1/rGel [23] was used as a positive control throughout the study.

Both SKOV-3 and SK-BR-3 cells were found to be
HER2-positive, although HER2 was more pronounced in SK-BR-3 cells in agreement with a previous report [39]. The increased level of HER2 found in SK-BR-3 cells could, however, not explain the $\sim 60$-fold higher TI (72 hrs incubation) of MH3-B1/rGel compared to the SKOV-3 cells or the significantly decreased sensitivity to MH3-B1 or trastuzumab in SKOV-3 cells. The mechanism of $\mathrm{MH} 3-\mathrm{B} 1 / \mathrm{rGel}$ toxicity is dual because it (i): inhibits HER2 signaling and function through MH3-B1 and (ii): induces toxicity through the rGel payload which acts intracellulary by inactivating ribosomes leading to a generalized inhibition of protein synthesis. SKOV3 cells have also previously been reported resistant to trastuzumab [28, 31]. Trastuzumab resistance in SKOV3 cells is shown to depend on a constitutive activation of AKT, caused by lack of the tumor suppressor protein RAS homolog member I and also on low expression of PTEN which is recruited to the plasma membrane upon trastuzumab-HER2 association and inhibits AKT as one of the main mechanisms of trastuzumab induced $\mathrm{G} 1$ arrest $[28,40]$. MH3-B1 binds to another domain of HER2 than trastuzumab (results not published). The present results show, however, that SKOV-3 cells are resistant also to MH3-B1. AKT inhibition post MH3-B1 treatment was not assessed in the present study, and has not been reported before. However, the observed cross-resistance between trastuzumab and MH3-B1 may indicate a partial overlapping mechanism of resistance between these two HER2-targeted compounds.

In our study, $72 \mathrm{hrs}$ treatment of $\mathrm{MH} 3-\mathrm{B} 1 / \mathrm{rGel}$ in SKOV-3 cells induced only minor toxicity by HER2 inhibition as shown by the MH3-B1-induced reduction in viability at comparable concentrations. Four hrs incubation of MH3-B1 did not induce any reduction in viability in SKOV-3 or SK-BR-3 cells at doses $<10 \mu \mathrm{M}$ (Fig. 2A and 2B). The $\sim 11$-fold increased TI of $\mathrm{MH} 3-\mathrm{B} 1 / \mathrm{rGel}$ in SKBR-3 cells compared to the SKOV-3 cell line after a $4 \mathrm{hrs}$ incubation of the toxins therefore indicate that SKOV-3 cells are resistant also to the gelonin-induced toxicity of $\mathrm{MH} 3-\mathrm{B} 1 / \mathrm{rGel}$.

PCI is a method for cytosolic release of therapeutics entrapped in endocytic vesicles [17]. Endocytic trapping and subsequent hydrolytic degradation of $\mathrm{MH} 3-\mathrm{B} 1 / \mathrm{rGel}$ as an important mechanism of resistance in SKOV-3 cells was shown by the efficacy of PCI in this cell line. The similar efficacy of PCI of MH3-B1/rGel (rGelcorrected PCI efficacy) in SKOV-3 and SK-BR-3 cells found (Fig. 3D), despite the 2 -fold higher MH3-B1/rGel accumulation in SK-BR-3 cells (Fig. 2D), also suggests a higher distribution of $\mathrm{MH} 3-\mathrm{B} 1 / \mathrm{rGel}$ to endocytic vesicles in SKOV-3 cells. The higher distribution of $\mathrm{MH} 3-\mathrm{B} 1 / \mathrm{rGel}$ in acidic vesicles in SKOV-3 cells is also reflected in the higher Pearson's correlation coefficient of MH3-B1/rGel and LTR found in this cell line (Fig. 2G). A more detailed mechanistic explanation on $\mathrm{MH} 3-\mathrm{B} 1 / \mathrm{rGel}$ resistance should be addressed in future studies. These studies may 
include siRNA targeting different cathepsins and also inhibitors of hydrolytic activity.

PCI of MH3-B1/rGel on SKOV-3 xenografts in nude mice also revealed significantly smaller tumors in the PCI group compared to all control groups when measured 16 days after light exposure. This in vivo effect was smaller than expected based on the presented in vitro results and also on other reports on PCI of geloninbased immunotoxins $[20,21]$. It has previously been shown that as little as $6.3 \times 10^{-12} \mathrm{moles} / \mathrm{g}$ tumor tissue is sufficient for complete remission with an immunotoxin based on PE (anti-Tac(Fv)-PE38) [41]. We have tried, by western blotting, to evaluate the amount of MH3-B1/ rGel present in SKOV-3 tumors $48 \mathrm{hrs}$ post i.v. injection of doses of $2 \mathrm{mg} / \mathrm{kg}(0.05 \mathrm{mg} /$ mouse $)$. We believe that this dose was likely below the limit of detection of our western analysis which was found to correspond to 3.78 $\mathrm{x} 10^{-12} \mathrm{moles} / \mathrm{g}$ tumor tissue. Compared to PE, rGel lacks a domain for cytosolic translocation [13]. If PCI can induce a $100 \%$ cytosolic release of $\mathrm{MH} 3-\mathrm{B} 1 / \mathrm{rGel}$, the 2 $\mathrm{mg} / \mathrm{kg}$ dose administered $48 \mathrm{hrs}$ prior to light exposure is still significant less than what has previously been indicated as a curative dose of PE. However, we find it highly promising that the small amount of tumor-localized MH3-B1/rGel appears to demonstrate antitumor activity in combination with PCI.

In the present study, only a single i.v. injection at a dose of $2 \mathrm{mg} / \mathrm{kg}$ was used. The increased efficacy provided by PCI has previously been shown to induce complete responses following only one injection of gelonin-based immunotoxins at comparable doses as here applied, however, the lack of severe adverse effects following $2 \mathrm{mg} / \mathrm{kg}$ of MH3-B1/rGel suggests that this dose may be increased to improve the PCI-induced efficacy. A significant effect on tumor growth delay has previously been reported after a fractionated dose $(6$ injections in 10 days) of $24 \mathrm{mg} / \mathrm{kg}$ MH3-B1/rGel [9]. This report therefore warrants a demonstration of higher single doses of $\mathrm{MH} 3-\mathrm{B} 1 / \mathrm{rGel}$, than currently available, in combination with PCI.

Altogether, the presented data suggest PCI of MH3-B1/rGel as a HER2-targeted treatment approach for HER2-positive cancers, including ovarian cancers resistant to HER2-targeted therapeutics. We have recently reported that PCI of MH3-B1/rGel exerts HER2-induced toxicity also in breast cancer with low HER2 expression [23]. PCI of MH3-B1/rGel may therefore be beneficial not only to the $\sim 35 \%$ of ovarian cancers with high HER2 expression, but also in cases with medium to low HER2 expression. Although also effective in HER2-low expressing cancer, the PCI-induced efficacy of MH3-B1/ rGel clearly correlates with HER2 expression [23] (Fig. 3). Off-target effects of the treatment in HER2 positive normal cells should, in addition, be of minor importance since off-target tissue in general (except in the liver) will accumulate less PS [42] and will not be subjected to light exposure. The present report warrants further evaluation in preclinical ovarian cancer models. These studies will also include pharmacologic evaluation to conclude on the mechanisms of cell death induced by the treatment. The in vivo protocol must, however, be optimized with respect to MH3-B1/rGel dose.

\section{MATERIALS AND METHODS}

\section{Cell lines and cultivation}

Four HER2 overexpressing cell lines were used in this study. The ovarian adenocarcinoma cell line SKOV3 (ATCC, HTB-77TM), purchased from American Type Culture Collection (ATCC, Manassas, VA, USA), the human breast adenocarcinoma cell line SK-BR-3, kindly provided by the Department of Biochemistry, Institute for Cancer Research, Norwegian Radium Hospital, Oslo University Hospital, Oslo, Norway, the human ovarian carcinoma cell line HOC-7, kindly provided by Dr. Yvonne Anderson, Department of Tumor Biology, Institute for Cancer Research, Norwegian Radium Hospital, Oslo University Hospital, Oslo, Norway, and the rat ovarian cancer cell line NuTu-19, originally a gift from Dr. A.L Major, University of Geneva, Switzerland [22]. The HER2 low expressing human breast adenocarcinoma cell line MDA-MB-468 (ATCC, HTB-132 $2^{\mathrm{TM}}$ ) was obtained from ATCC. SKOV-3 and SK-BR-3 cells were cultured in McCoy's 5A medium while HOC-7 and NuTu-19 cells were cultured in RPMI 1640 medium. Both media were obtained from Sigma-Aldrich (St. Louis MO) and modified as previously described [23]. The MDA-MB-468 cells were cultured in Leibovitz's L-15 medium (Lonza, Basel, Switzerland) modified as previously described [23] with free gas exchange with atmospheric air.

\section{Preparation of MH3-B1 and MH3-B1/rGel}

The HER2-targeted single chain antibody-fragment MH3-B1 and the HER2-targeted recombinant fusion toxin $\mathrm{MH} 3-\mathrm{B} 1 / \mathrm{rGel}$ were produced as previously reported [9]. rGel is the recombinant version of the type I RIP gelonin.

\section{Evaluation of cytotoxicity}

The MTT viability assay was in the present study used to assess cytotoxicity of the different treatments. Cytotoxicity data, as measured by clonal cell survival, has previously been compared with MTT data as obtained here $[24,25]$. No significant difference has been observed in these studies. 


\section{Evaluation of HER2-targeted therapeutics}

Cells were seeded at $2.5 \times 10^{3}$ (SKOV-3), 6.0 $\times 10^{3}$ (SK-BR-3), $2 \times 10^{3}$ (HOC-7) and $1.5 \times 10^{3}$ (NuTu-19) cells/ well in 96-well plates (Nunc) and allowed to attach to the substratum overnight. The cells were then subjected to a $72 \mathrm{hrs}$ incubation of increasing concentrations of trastuzumab (Hoffmann-La Roche, Basel, Switzerland) or the scFv MH3-B1. To examine the cytotoxicity of the immunotoxin $\mathrm{MH} 3-\mathrm{B} 1 / \mathrm{rGel}$, the cells were incubated with MH3-B1/rGel or rGel for 4 or $72 \mathrm{hrs}$ and the MTT viability assay was done $72 \mathrm{hrs}$ post treatment initiation for both incubation procedures as previously reported [23]. $\mathrm{IC}_{50}$ ( $72 \mathrm{hrs}$ incubation) or $\mathrm{IC}_{35}$ (4 hrs incubation) values of MH3-B1/rGel and rGel were calculated from sigmoidal curves (see 2.11) and used for establishing the targeting index (TI) of MH3-B1/rGel:

\section{Targeting index ${ }_{I C 50}=\frac{I C_{50} \mathrm{rGel}}{I C_{50} M H 3-\mathrm{B} 1 / \mathrm{rGel}}$}

*Formula for calculating the $\mathrm{TI}$ at $\mathrm{IC}_{50}\left(\mathrm{TI}_{50}\right)$ for rGel and $\mathrm{MH} 3-\mathrm{B} 1 / \mathrm{rGel}$. The $\mathrm{TI}_{\text {at }} \mathrm{IC}_{35}\left(\mathrm{TI}_{35}\right)$ was assessed by the same formula inserting the $\mathrm{IC}_{35}$ values.

\section{Light source}

The cells were exposed to light from LumiSource ${ }^{\circledR}$ (PCI Biotech AS, Oslo, Norway), delivering blue light $\left(\lambda_{\max }=435 \mathrm{~nm}\right)$ from a bank of four 18W Osram L 18/67 light tubes with an irradiance of $12.6 \mathrm{~mW} / \mathrm{cm}^{2}$, varying less than $10 \%$ across the illumination area.

\section{PCI of MH3-B1/rGel in vitro}

The PS TPCS $2 \mathrm{a}$ (meso-tetraphenyl chlorin with two sulfonate groups on adjacent phenyl rings, Amphinex ${ }^{\circledR}$ ) was provided by PCI Biotech AS. Experiments with $\mathrm{TPCS}_{2 \mathrm{a}}$ were performed under subdued light. Cells were seeded at $10 \times 10^{3}$ (SK-BR-3), $5 \times 10^{3}$ (SKOV-3), $3 \times 10^{3}$ (HOC-7) and $2 \times 10^{3}$ (NuTu-19) cells/well in 96-well plates (Nunc) and allowed to attach for $6 \mathrm{hrs}$. MDA-MB-468 were seeded at $8 \times 10^{3}$ cells/well and attached over night. Cells were then subjected to $0.4 \mu \mathrm{g} / \mathrm{ml}$ (SK-BR-3, SKOV3 , HOC-7 and NuTu-19) or $0.1 \mu \mathrm{g} / \mathrm{ml}$ (MDA-MB-468) $\mathrm{TPCS}_{2 \mathrm{a}}$ for $18 \mathrm{hrs}$, washed twice with culture medium and incubated with $2 \mathrm{nM} \mathrm{MH3}-\mathrm{B} 1 / \mathrm{rGel}$ for $4 \mathrm{hrs}$ before the medium was replaced with new drug-free culture medium and the cells exposed to increasing doses of light from LumiSource ${ }^{\circledR}$. All treatment regimens were performed in triplicates and the MTT assay was used for cell viability evaluation 48 hrs (SK-BR-3, HOC-7, NuTu-19 and MDAMB-468) or 96 hrs (SKOV-3) after light exposure as previously reported [23]. PCI efficacy was corrected for cellular sensitivity to rGel treatment as follows [23]:

rGel-corrected PCI efficacy $\left(L D_{50}\right)=\frac{P C I \text { efficacy } x I C_{50} r G e l}{100}$

where PCI efficacy is described as:

$P C I$ efficacy $=\frac{\text { Photochemical treatment } L D_{50}}{P C I L D_{50}}$

where the photochemical treatment is the combination of PS and light without any protein toxin added and $\mathrm{IC}_{50}$ rGel refers to the rGel concentration in nM.

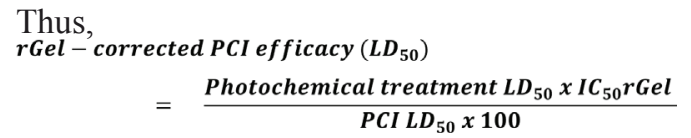

\section{Western blot analysis}

For assessment of HER2 expression, sample preparation and western blotting were performed as previously described [23]. Three different substrate detection systems were used on the Western blots dependent on the band signal; LumiGlo chemiluminescent substrate system (KPL, Gaithesburg, MD USA), Supersignal West Dura Extended duration Substrate (Thermo Scientific, Rockford, IL, USA) and Supersignal West Femto Maximum Sensitivity Substrate (Thermo Scientific). Unfortunately, we were not able to find any antibody recognizing rat HER2.

For detection of HER 2 and MH3-B1/rGel in SKOV3 tumors, MH3-B1/rGel was injected i.v. at $2 \mathrm{mg} / \mathrm{kg}$ when the tumors reached $200 \mathrm{~mm}^{3}$. The tumors were harvested $48 \mathrm{hrs}$ post injection and prepared as previously described [26]. Prior to SDS-PAGE, the samples were mixed with $5 \mathrm{x}$ reducing buffer and western blotting was performed as recently described [23]. The primary anti-gelonin polyclonal antibody was established by the Rosenblum lab.

\section{Cellular uptake and localization of Alexa488- MH3-B1/rGel}

Alexa488-labeled MH3-B1/rGel was prepared as recently described [23]. For evaluation of cellular uptake of Alexa488-MH3-B1/rGel, cells were seeded at $4 \times 10^{5}$ (SK-BR-3) and $3 \times 10^{5}$ (SKOV-3) cells/well in 6-well plates and treated and analyzed as previously reported by a BD FACSCalibur ${ }^{\mathrm{TM}}$ flow cytometer and BD CellQuest ${ }^{\mathrm{TM}}$ software (Becton-Dickinson) [23].

Alexa488-MH3-B1/rGel was also used to evaluate the cellular localization of MH3-B1/rGel by confocal microscopy in the presence of Lysotracker ${ }^{\circledR}$ (LTR) as recently reported [23].

To calculate the degree of overlap between the 
chromophores Alexa488-MH3-B1/rGel and LTR, the weighted colocalization coefficient Manders' thresholded coefficient (MTC) was used. The calculation of the MTC designates the sum of intensities of colocalizing pixels in the respective channel, as compared to the overall sum of pixel intensities above threshold and formulated by:

$$
M T C=\frac{\sum C h 1_{i, \text { coloc }}}{\sum \operatorname{Ch} 1_{i}}
$$

where $\mathrm{Ch} 1_{i, \text { coloc }}$ is the fluorescence intensity of Alexa488-MH3-B1/rGel in each pixel where the intensity of LTR is above threshold, and $\Sigma \mathrm{Ch} 1_{i}$ is the sum of Alexa488-MH3-B1/rGel pixel intensities above threshold in the cells. A threshold was set above the noise level for each chromophore, and was determined by imaging control cells in the absence of LTR and PS. The same threshold was used in all cells [27].

The Pearson's correlation coefficient (PCC) was used to calculate the correlation between the fluorescence intensity of Alexa488-MH3-B1/rGel and LTR where a value of 1 represents $100 \%$ positive correlation, 0 indicates no correlation and -1 represents a total negative correlation formulated by:

$$
=\frac{\sum\left(C h 1_{i}-C h 1_{a v g}\right)\left(C h 2_{i}-C h 2_{a v g}\right)}{\sqrt{\sum\left(\left(C h 1_{i}-C h 1_{\text {avg }}\right)^{2}\left(C h 2_{i}-C h 2_{\text {avg }}\right)^{2}\right)}}
$$

where $\mathrm{Ch} 1_{i}$ and $\mathrm{Ch} 2_{i}$ is the fluorescence intensity from Alexa488-MH3-B1/rGel and LTR in each pixel, respectively, and $\mathrm{Ch} 1_{\text {avg }}$ and $\mathrm{Ch} 2_{\text {avg }}$ are the average intensity values of the two chromophores [27]. All calculations were made from nine measured cells from three independent experiments.

\section{PCI of MH3-B1/rGel in vivo}

All handling of animals were performed according to standards set by the institutional animal care and use committee, in compliance with the Norwegian Animal Research Authority's guidelines. Cultured subconfluent SKOV-3 cells were injected subcutaneously on the left leg of Hsd:Athymic Nude-Foxn $1^{n u}$ female mice $\left(5 \times 10^{6}\right.$ cells/animal). At a tumor size of $75-225 \mathrm{~mm}^{3}$, the mice were randomly assigned to 4 treatment groups; no treatment, $\mathrm{MH} 3-\mathrm{B} 1 / \mathrm{rGel}$, photochemical treatment and PCI of MH3-B1/rGel. The PS TPCS ${ }_{2 \mathrm{a}}$ was administered intravenously at $5 \mathrm{mg} / \mathrm{kg} 72 \mathrm{hrs}$ prior to light exposure and $2 \mathrm{mg} / \mathrm{kg}$ (100 $\mu \mathrm{l}$ of $0.534 \mathrm{mg} / \mathrm{ml}$ stock solution) of MH3-B1/rGel was injected intravenously $24 \mathrm{hrs}$ or $48 \mathrm{hrs}$ before light exposure. Tumors were illuminated by a 652 $\mathrm{nm}$ diode laser (CeramOptec GmbH, Bonn, Germany) equipped with a laserfiber (Medlight SA, Ecublens, Switzerland) at an irradiance of $90 \mathrm{~mW} \mathrm{~cm}^{-2}$ and a total dose of $20 \mathrm{~J} \mathrm{~cm}^{-2}$. Sevoflurane inhalation gas was used as an anesthetic during light exposure and body temperature was maintained by placing the animal on a water-heated plate. The mice were covered by aluminum foil during light exposure, exposing only the tumor area and a $\sim 2 \mathrm{~mm}$ margin to light. Tumor volume, measured by a caliper, and weight were monitored 2-3 times a week. Tumor volume was calculated by the equation; $0.5 \times L \times W^{2}(\mathrm{~L}=$ length and $\mathrm{W}=$ width of tumor). Animals were euthanized by cervical dislocation when tumor volume exceeded 1000 $\mathrm{mm}^{3}$.

\section{Assessment of liver and kidney toxicity}

The animals were divided in 2 groups: no-treatment and PCI of MH3-B1/rGel with 4 animals in each group. The animals were anesthetized and subjected to cardiac puncture $24 \mathrm{hrs}$ after light exposure when $1 \mathrm{ml}$ whole blood was transferred with a $1 \mathrm{ml}$ syringe (27 G Kidneys) to a $4 \mathrm{ml} \mathrm{LH}$ Lithium Heparin Separator (Greiner Bio One, Austria). The tubes were subjected to a 15 min centrifugation at $2500 \mathrm{G}$ and serum aspartate aminotransferase (AST), alanine aminotransferase (ALT) and creatinine were assayed on a Cobas6000 (Roche Diagnostics, Mannheim, Germany) within 1.5 hrs after blood sampling. and liver were removed immediately after cardiac puncture and fixed 3 days in formalin prior to H\&E staining as previously described [21]. One of the PCI of MH3-B1/rGel treated animals was excluded from the study due to difficulties with the cardiac puncture.

\section{Statistical analysis}

Sigmaplot $^{\mathrm{TM}}$ version 12.5 (Systat Software Inc., San Jose, CA, USA) and IBM SPSS (IBM Corporation, Armonk, New York, US) were used for statistical analysis. A 2-sided Student's t-test was used to measure statistical differences and a value of $p<0.05$ was considered statistically significant.

\section{ACKNOWLEGEMENTS}

We thank Theeba Pratheesh for excellent technical assistance and the Flow Cytometry- and Confocal Microscopy- Core Facilities at the Institute for Cancer Research, The Norwegian Radium Hospital, Oslo University Hospital for invaluable assistance. We also thank chief attending physician Nils Bolstad at Department of Medical Biochemistry, Norwegian Radium Hospital, Oslo University Hospital for technical assistance in creatinine, AST and ALT measurements and the Norwegian Cancer Society and The Norwegian Radium Legacies for financial support. This project was conducted, in part, by the Clayton Foundation for Research. 


\section{CONFLICT OF INTEREST}

None

\section{Abbreviations}

ALT: Alanine aminotransferase, AST: Aspartate aminotransferase, HER2: Human epidermal growth factor receptor 2, LTR: Lysotracker, mAb: Monoclonal antibody, PCI: Photochemical internalization, PE: Pseudomonas exotoxin, PS: Photosensitizer, rGel: recombinant gelonin, RIP: Ribosome-inactivating protein, TI: Targeting index, TKI: Tyrosine kinase inhibitor, TPCS $_{2 \mathrm{a}}$ : Mesotetraphenylchlorin with two sulfonate groups on adjacent phenyl rings

\section{REFERENCES}

1. Hynes NE, Stern DF. The biology of erbB-2/neu/HER-2 and its role in cancer. Biochim.Biophys.Acta. 1994; 1198: 165-184.

2. Mohamed A, Krajewski K, Cakar B, Ma CX. Targeted therapy for breast cancer. Am.J.Pathol. 2013; 183: 10961112.

3. Bookman MA, Darcy KM, Clarke-Pearson D, Boothby RA, Horowitz IR. Evaluation of monoclonal humanized anti-HER2 antibody, trastuzumab, in patients with recurrent or refractory ovarian or primary peritoneal carcinoma with overexpression of HER2: a phase II trial of the Gynecologic Oncology Group. J.Clin.Oncol. 2003; 21: 283-290.

4. Weroha SJ, Oberg AL, Ziegler KL, Dakhilm SR, Rowland KM, Hartmann LC, Moore DF, Jr., Keeney GL, Peethambaram PP, Haluska P. Phase II trial of lapatinib and topotecan (LapTop) in patients with platinum-refractory/ resistant ovarian and primary peritoneal carcinoma. Gynecol.Oncol. 2011; 122: 116-120.

5. Gordon MS, Matei D, Aghajanian C, Matulonis UA, Brewer M, Fleming GF, Hainsworth JD, Garcia AA, Pegram MD, Schilder RJ, Cohn DE, Roman L, Derynck MKet al. Clinical activity of pertuzumab (rhuMAb 2C4), a HER dimerization inhibitor, in advanced ovarian cancer: potential predictive relationship with tumor HER2 activation status. J.Clin. Oncol. 2006; 24: 4324-4332.

6. Verri E, Guglielmini P, Puntoni M, Perdelli L, Papadia A, Lorenzi P, Rubagotti A, Ragni N, Boccardo F. HER2/neu oncoprotein overexpression in epithelial ovarian cancer: evaluation of its prevalence and prognostic significance. Clinical study. Oncology. 2005; 68: 154-161.

7. Farley J, Fuchiuji S, Darcy KM, Tian C, Hoskins WJ, McGuire WP, Hanjani P, Warshal D, Greer BE, Belinson J, Birrer MJ. Associations between ERBB2 amplification and progression-free survival and overall survival in advanced stage, suboptimally-resected epithelial ovarian cancers: a Gynecologic Oncology Group Study. Gynecol.Oncol. 2009;
113: 341-347.

8. Cao Y, Marks JD, Marks JW, Cheung LH, Kim S, Rosenblum MG. Construction and characterization of novel, recombinant immunotoxins targeting the Her2/neu oncogene product: in vitro and in vivo studies. Cancer Res. 2009; 69: 8987-8995.

9. Cao Y, Marks JD, Huang Q, Rudnick SI, Xiong C, Hittelman WN, Wen X, Marks JW, Cheung LH, Boland K, Li C, Adams GP, Rosenblum MG. Single-chain antibody-based immunotoxins targeting Her2/neu: design optimization and impact of affinity on antitumor efficacy and off-target toxicity. Mol.Cancer Ther. 2012; 11: 143153.

10. Cao Y, Marks JW, Liu Z, Cheung LH, Hittelman WN, Rosenblum MG. Design optimization and characterization of Her2/neu-targeted immunotoxins: comparative in vitro and in vivo efficacy studies. Oncogene. 2014; 33: 429-439.

11. Azemar M, Schmidt M, Arlt F, Kennel P, Brandt B, Papadimitriou A, Groner B, Wels W. Recombinant antibody toxins specific for ErbB2 and EGF receptor inhibit the in vitro growth of human head and neck cancer cells and cause rapid tumor regression in vivo. Int.J.Cancer. 2000; 86: 269-275

12. Stirpe F, Olsnes S, Pihl A. Gelonin, a new inhibitor of protein synthesis, nontoxic to intact cells. Isolation, characterization, and preparation of cytotoxic complexes with concanavalin A. J Biol.Chem. 1980; 255: 6947-6953.

13. Barbieri L, Battelli MG, Stirpe F. Ribosome-inactivating proteins from plants. Biochim.Biophys.Acta. 1993; 1154: 237-282.

14. Pirie CM, Hackel BJ, Rosenblum MG, Wittrup KD. Convergent potency of internalized gelonin immunotoxins across varied cell lines, antigens, and targeting moieties. J.Biol.Chem. 2011; 286: 4165-4172.

15. Berg K, Selbo PK, Prasmickaite L, Tjelle TE, Sandvig K, Moan J, Gaudernack G, Fodstad O, Kjolsrud S, Anholt H, Rodal GH, Rodal SK, Hogset A. Photochemical internalization: a novel technology for delivery of macromolecules into cytosol. Cancer Res. 1999; 59: 11801183.

16. Weyergang A, Selbo PK, Berstad MB, Bostad M, Berg K. Photochemical Internalization of Tumor-Targeted Protein Toxins. Lasers in Surgery and Medicine. 2011; 43: 721-733.

17. Selbo PK, Weyergang A, Hogset A, Norum OJ, Berstad MB, Vikdal M, Berg K. Photochemical internalization provides time- and space-controlled endolysosomal escape of therapeutic molecules. J.Control Release. 2010; 148: 2-12.

18. Selbo PK, Sivam G, Fodstad O, Sandvig K, Berg K. In vivo documentation of photochemical internalization, a novel approach to site specific cancer therapy. Int J Cancer. 2001; 92: 761-766.

19. Berg K, Dietze A, Kaalhus O, Hogset A. Site-specific drug delivery by photochemical internalization enhances the 
antitumor effect of bleomycin. Clin.Cancer Res. 2005; 11: 8476-8485.

20. Selbo PK, Rosenblum MG, Cheung LH, Zhang W, Berg K. Multi-modality therapeutics with potent anti-tumor effects: photochemical internalization enhances delivery of the fusion toxin scFvMEL/rGel. PLoS.One. 2009; 4: e6691-

21. Weyergang A, Cheung LH, Rosenblum MG, Mohamedali KA, Peng Q, Waltenberger J, Berg K. Photochemical internalization augments tumor vascular cytotoxicity and specificity of VEGF121/rGel fusion toxin. J.Control Release. 2014; 180: 1-9.

22. Major AL, Rose GS, Chapman CF, Hiserodt JC, Tromberg BJ, Krasieva TB, Tadir Y, Haller U, DiSaia PJ, Berns MW. In vivo fluorescence detection of ovarian cancer in the NuTu-19 epithelial ovarian cancer animal model using 5-aminolevulinic acid (ALA). Gynecol.Oncol. 1997; 66: 122-132.

23. Bull-Hansen B, Cao Y, Berg K, Skarpen E, Rosenblum MG, Weyergang A. Photochemical activation of the recombinant HER2-targeted fusion toxin MH3-B1/rGel; Impact of HER2 expression on treatment outcome. J.Control Release. 2014; 182: 58-66.

24. Yip WL, Weyergang A, Berg K, Tonnesen HH, Selbo PK. Targeted delivery and enhanced cytotoxicity of cetuximabsaporin by photochemical internalization in EGFR-positive cancer cells. Mol.Pharm. 2007; 4: 241-251.

25. Bostad M, Kausberg M, Weyergang A, Olsen CE, Berg K, Hogset A, Selbo PK. Light-Triggered, Efficient Cytosolic Release of IM7-Saporin Targeting the Putative Cancer Stem Cell Marker CD44 by Photochemical Internalization. Mol. Pharm. 2014; 11: 2764-2776.

26. Weyergang A, Selbo PK, Berg K. Y1068 phosphorylation is the most sensitive target of disulfonated tetraphenylporphyrin-based photodynamic therapy on epidermal growth factor receptor. Biochem.Pharmacol. 2007; 74: 226-235.

27. Vikdal M, Generalov R, Berg K. The photosensitizer disulfonated aluminum phthalocyanine reduces uptake and alters trafficking of fluid phase endocytosed drugs in vascular endothelial cells-Impact on efficacy of photochemical internalization. Biochem.Pharmacol. 2013; 86: 748-758.

28. Longva KE, Pedersen NM, Haslekas C, Stang E, Madshus IH. Herceptin-induced inhibition of ErbB2 signaling involves reduced phosphorylation of Akt but not endocytic down-regulation of ErbB2. Int.J.Cancer. 2005; 116: 359367.

29. Wilken JA, Webster KT, Maihle NJ. Trastuzumab Sensitizes Ovarian Cancer Cells to EGFR-targeted Therapeutics. J.Ovarian.Res. 2010; 3: 7-3.

30. Lewis GD, Figari I, Fendly B, Wong WL, Carter P, Gorman C, Shepard HM. Differential responses of human tumor cell lines to anti-p185HER2 monoclonal antibodies. Cancer Immunol.Immunother. 1993; 37: 255-263.
31. Bijman MN, van Berkel MP, Kok M, Janmaat ML, Boven E. Inhibition of functional HER family members increases the sensitivity to docetaxel in human ovarian cancer cell lines. Anticancer Drugs. 2009; 20: 450-460.

32. Berg K, Weyergang A, Prasmickaite L, Bonsted A, Hogset A, Strand MT, Wagner E, Selbo PK. Photochemical internalization (PCI): a technology for drug delivery. Methods Mol.Biol. 2010; 635:133-45.: 133-145.

33. Tjelle TE, Brech A, Juvet LK, Griffiths G, Berg T. Isolation and characterization of early endosomes, late endosomes and terminal lysosomes: their role in protein degradation. J.Cell Sci. 1996; 109: 2905-2914.

34. Bohley P, Seglen PO. Proteases and proteolysis in the lysosome. Experientia. 1992; 48: 151-157.

35. Zhang N, Liu L, Dumitru CD, Cummings NR, Cukan M, Jiang Y, Li Y, Li F, Mitchell T, Mallem MR, Ou Y, Patel RN, Vo Ket al. Glycoengineered Pichia produced antiHER2 is comparable to trastuzumab in preclinical study. MAbs. 2011; 3: 289-298.

36. Marcus CS, Maxwell GL, Darcy KM, Hamilton CA, McGuire WP. Current Approaches and Challenges in Managing and Monitoring Treatment Response in Ovarian Cancer. J.Cancer. 2014; 5: 25-30.

37. Nielsen JS, Jakobsen E, Holund B, Bertelsen K, Jakobsen A. Prognostic significance of p53, Her-2, and EGFR overexpression in borderline and epithelial ovarian cancer. Int.J.Gynecol.Cancer. 2004; 14: 1086-1096.

38. Sheng Q, Liu J. The therapeutic potential of targeting the EGFR family in epithelial ovarian cancer. Br.J.Cancer. 2011; 104: 1241-1245.

39. Fazio-Eli L, Strommen K, Dao-Pick T, Parry G, Goodman L, Winslow J. Quantitative assays for the measurement of HER1-HER2 heterodimerization and phosphorylation in cell lines and breast tumors: applications for diagnostics and targeted drug mechanism of action. Breast Cancer Res. 2011; 13: R44-

40. Faratian D, Goltsov A, Lebedeva G, Sorokin A, Moodie S, Mullen P, Kay C, Um IH, Langdon S, Goryanin I, Harrison DJ. Systems biology reveals new strategies for personalizing cancer medicine and confirms the role of PTEN in resistance to trastuzumab. Cancer Res. 2009; 69: 6713-6720.

41. Kreitman RJ, Pastan I. Accumulation of a recombinant immunotoxin in a tumor in vivo: fewer than 1000 molecules per cell are sufficient for complete responses. Cancer Res. 1998; 58: 968-975.

42. Berg K, Nordstrand S, Selbo PK, Tran DT, ngell-Petersen E, Hogset A. Disulfonated tetraphenyl chlorin (TPCS2a), a novel photosensitizer developed for clinical utilization of photochemical internalization. Photochem.Photobiol.Sci. 2011; 10: 1637-1651. 